\title{
O USO DE UM AMBIENTE VIRTUAL DE APRENDIZAGEM COMO APOIO PARA O ENSINO DE INGLÊS NA PERSPECTIVA DE LÍNGUA COMO DISCURSO
}

\author{
THE USE OF A VIRTUAL LEARNING ENVIRONMENT TO SUPPORT ENGLISH \\ TEACHING FROM THE PERSPECTIVE OF LANGUAGE AS SPEECH
}

\author{
Adriana Cristina Sambugaro de Mattos Brahim ${ }^{1}$ \\ Edna Marta Oliveira da Silva ${ }^{2}$ \\ Iara Maria Bruz ${ }^{3}$
}

\begin{abstract}
RESUMO: O presente artigo tem por objetivo apresentar algumas reflexões a respeito do uso de ambientes virtuais de aprendizagem no ensino de língua inglesa em um curso de graduação de Secretariado Executivo Trilíngue na modalidade presencial, a partir de uma pesquisa realizada em uma instituição de ensino superior (IES). São apresentadas algumas questões sobre o impacto das tecnologias nos modos de vida dos indivíduos e do uso das tecnologias de informação e comunicação (TICs) no âmbito educacional. Em se tratando dos processos de aprendizagem mediado pelas TICs, discutiremos aspectos relacionados ao ciberespaço e às possibilidades de seu uso em ambientes virtuais de aprendizagem (AVA). Nesse sentido, não poderíamos deixar à parte a discussão a respeito da interatividade, característica da Web 2.0 e, consequentemente, como os estudos sobre o interacionismo proposto por Vygotsky podem ser aí aplicados. Ainda, por tratarmos de língua estrangeira, concepções sobre língua são apresentadas e vinculadas ao seu ensino mediado pelas TICs. Por fim, são apresentadas conclusões e possibilidades obtidas a partir da pesquisa realizada com alunos do curso de Secretariado Executivo Trilíngue em relação ao uso de um AVA durante dois semestres letivos. A pesquisa mostrou que apenas o uso do AVA não leva o aluno a utilizar a língua alvo dentro de uma concepção de língua como discurso.
\end{abstract}

PALAVRAS-CHAVE: ambientes virtuais de aprendizagem; TICs; língua inglesa; ensino e aprendizagem.

\begin{abstract}
The present article aims to present some reflections on the use of learning management system environments in the teaching of English language in a Trilingual Office Management undergraduate course from a research conducted in an institution of higher education. Some questions about the impact of technologies in the way of life of the individuals and the use of information and communication technologies (ICTs) within education are presented. In the case of the learning processes mediated by ICTs, we intend to discuss some aspects related to cyberspace and the tools available on the Web 2.0 as well as the possibilities for their use in learning management systems (LMS) which presence is paramount in distance education courses. In this sense, it is necessary to mention some issues on about interactivity, which is a fundamental characteristic of the Web 2.0 and, consequently, as the studies on the interactionism proposed by Vygotsky can be applied to such space. Moreover, as we are dealing with a foreign language, conceptions about language are presented and linked to its teaching mediated by ICTs. Finally, conclusions and possibilities obtained from the study

\footnotetext{
${ }^{1}$ Doutora em Linguística Aplicada pela Unicamp. Mestre Linguística Aplicada pela mesma instituição. professora titular de língua inglesa da UFPR. E-mail: adrianacsmbrahim@ gmail.com

${ }_{2}^{2}$ Mestranda em Estudos Linguísticos pela UFPR. Especialista em Ensino de Línguas Estrangeiras Modernas pela UTFPR. Professora de língua inglesa do Centro Universitário Internacional Uninter. Email: tecasilva@gmail.com

${ }^{3}$ Doutoranda em Estudos Linguísticos pela UFPR. Mestre em Educação pela mesma instituição. Professora do curso de Letras da FACEL. E-mail: iarabruz@gmail.com
} 
carried out with undergraduate students of the Trilingual Office Management course in relation to the use of a AVA during two school semesters are presented.

KEY WORDS: learning management systems; ICTs; English language; teaching and learning.

\section{Introdução}

Um processo de ensino e aprendizagem que seja bem sucedido deve levar o aprendente a poder prosseguir autonomamente no seu aprendizado , uma vez que ninguém pode perpetuar seu papel como aluno. Daí se depreende que a autonomia na aprendizagem é um objetivo desejável por todos. (MAGNO E SILVA, p. 51, 2009)

Desde tempos remotos, o homem se vale de sua inteligência não somente para transformar os recursos disponíveis ao seu redor em ferramentas que garantam a sua sobrevivência, mas também para a transmissão e informação de conhecimentos adquiridos. Os objetos feitos a partir de madeira, pedras e ossos, foram os primeiros artefatos humanos que puderam garantir aos nossos ancestrais a sua sobrevivência em um ambiente totalmente hostil.

O sucesso desses primeiros instrumentos, ainda que rudimentares, trouxe impactos profundos nas primeiras formações humanas, pois permitiram que alguns grupos suplantassem outros, garantindo assim a sua primazia. No decorrer dos tempos, novas invenções humanas surgiram em consonância com as necessidades, a ponto de ser praticamente impossível não atrelar o desenvolvimento humano ao das tecnologias. Da invenção da roda até o microchip do computador, da sociedade da informação, a tecnologia transformou as relações entre os seres humanos e destes, com a natureza. "A evolução social do homem confunde-se com as tecnologias desenvolvidas e empregadas em cada época. Diferentes períodos da história da humanidade são historicamente reconhecidos pelo avanço tecnológico correspondente" (KENSKI, 2007, p. 21). Criar novas tecnologias implica, diretamente, em alterar comportamentos e "a banalização do uso de determinada tecnologia impõe-se à cultura existente e transformam não apenas o comportamento individual, mas de todo o grupo social“" (op.cit.).

E, somado isso, existem novos estudos em relação ao ensino/aprendizagem de língua estrangeira. Alguns, preocupados com o livro didático e seu uso em sala de aula (BRUZ, 2012; PORCELLATO, 2013); outros, com o ensino e aprendizagem (DUBOC, 2012) e novas maneiras de perceber a língua (PENNYCOOK, 2012; WANG, et al, 2014). Assim, pensamos ser relevante pesquisar como o uso de uma tecnologia pode ser uma ferramenta útil para professores e, ainda, se esta ferramenta ajuda tanto o(a) aluno(a) quanto o professor(a) a 
colocarem em prática o uso autêntico de língua como parte integrante das aulas. Já existem algumas pesquisas nesse sentido (ROJO, 2013; MONTE MÓR, 2010, entre outros), pois a presença da tecnologia na vida dos sujeitos é uma realidade tanto para alunos quanto para professores.

Com base nessas reflexões, o presente artigo foi organizado da seguinte maneira: primeiro, discorreremos sobre a tecnologia e seu histórico; num segundo momento, sobre Ambiente Virtual de Aprendizagem (doravante, AVA) e o interacionismo com base nos estudos de Vygotsky. Em seguida apresentaremos brevemente uma reflexão sobre o conceito de língua e suas implicações com relação ao uso da tecnologia em sala de aula de língua inglesa, pois é o caso deste estudo. Finalmente, discutiremos a pesquisa em questão, feita por meio de análise de questionários respondidos pelos alunos de graduação que participaram da pesquisa sobre o uso do AVA nas aulas de língua inglesa. Terminamos com conclusões e algumas possibilidades que surgiram no decorrer dessa mesma pesquisa. ${ }^{4}$

\section{Sobre Tecnologia}

Vivemos, atualmente, não somente imersos, mas também com um alto grau de dependência da tecnologia. Para Bastos (2000), em todos os segmentos da sociedade é marcante a presença de tecnologias, desde um simples lápis até uma estação espacial em órbita terrestre. A própria escrita por meio da qual comunicamos ideias, sentimentos e atribuímos significados ao mundo ao nosso redor é uma "tecnologia de registro de som [...] e a leitura torna-se uma tecnologia desenvolvida pelo homem na decodificação de uma notação muito feliz" (RIBEIRO, 2005, p. 126). Portanto, seria alienante se ficássemos alheios a elas, uma vez que sofremos sua influência direta em nosso cotidiano, em nossas mais simples ações. Entretanto, há uma forte tendência em entendermos "tecnologias" como somente aquelas ligadas às comunicações e às informações. De fato, ao longo das últimas décadas do século XX, pudemos testemunhar um avanço em termos de tecnologias de informação e comunicação (doravante, TIC) que revolucionaram e mudaram, definitivamente, a forma como nos comunicamos e nos relacionamos. Desktops, notebooks, tablets, câmeras digitais, celulares e demais aparelhos eletrônicos compõe uma pequena amostra das possibilidades de uso de textos, sons e áudios e imagens estáticas ou em movimento que, até o início dos anos

\footnotetext{
${ }^{4}$ Este é um recorte da pesquisa realizada pelo grupo de pesquisas “A utilização do AVA no Ensino do Inglês" e estava vinculado ao Centro Universitário Internacional Uninter (2012-2013).
} 
90 do século passado, soariam como histórias de ficção científica. Isso sem mencionarmos a própria internet que tem o seu papel de destaque no processo de globalização ao final do século XX, pois a partir do momento em que deixou de ter usos restritos (com objetivos militares e de pesquisa) e passou a ser utilizada em vários campos do conhecimento humano, conquistou o seu papel de destaque na troca de informações, aproximando os mais diferentes povos.

As TIC e a internet permitiram a comunicação em rede, com maior velocidade de transmissão, facilitando o acesso a diferentes tipos de conhecimento. Com isso, opiniões, acontecimentos, notícias passaram a ser compartilhados de forma quase instantânea em diversos espaços na rede. Isso permitiu a cada usuário dos recursos da web tornar-se um ser mais participativo quando opina sobre as mais diversas realidades; aos moldes de um jornalista, quando consegue publicar em tempo real um acontecimento de sua cidade, e assim por diante. É também dentro desse ambiente, que um indivíduo pode, inclusive, virar um pouco "professor", de si mesmo e de outros. O conhecimento está, agora, a um clique de distância de um mouse.

Brito e Purificação (2006) referem-se à educação como algo inexorável e da qual ninguém escapa. "Todos os dias misturamos vida e educação" (BRITO e PURIFICAÇÃO, 2006, p. 19). A democratização do conhecimento obriga-nos a rever as propostas educacionais que deem conta do panorama que se delineia no século XXI. O espaço escolar não é o único lugar no qual processos educacionais ocorrem; ele é parte constituinte da sociedade informatizada e, como tal, não pode ficar à parte de sua função formadora de cidadãos. Faz-se necessário pensar em propostas que possam dar conta de atender aos objetivos educacionais em consonância com a era da informação e da sociedade do conhecimento: "questões da didática, dos métodos de ensino, dos conteúdos curriculares, para poder encontrar caminhos mais adequados e congruentes com o momento histórico em que estamos vivendo" (MORAES, 1998, p. 1).

No contexto educacional, os avanços tecnológicos acabaram por ser incorporados às práticas pedagógicas. A partir do uso em sociedade, foram sendo observadas outras aplicações possíveis no espaço escolar. Tal é o caso do livro, do rádio, do videocassete, do cinema, do CD player, do DVD player e, mais recentemente dos computadores e da própria internet. Em se tratando do ensino de idiomas, o uso de recursos extras como fotos, vídeos, músicas, além do material didático, é uma prática corrente entre boa parte dos docentes de língua estrangeira (doravante, LE), pois com isso pretende-se aproximar os discentes de contextos autênticos nos 
quais a LE pode ser o idioma usado para a comunicação. Com o uso desses recursos, não somente torna-se possível um maior acesso à LE em contextos autênticos de uso, mas também são criadas possibilidades de interações reais com outros aprendizes ao redor do mundo.

E assim sendo, as TIC apresentam-se como um recurso atrativo a ser utilizado no processo de mediação do conhecimento, pois podem proporcionar relações de ensino e aprendizagem mais autônomas. Quando utilizadas adequadamente pelos atores envolvidos nessas relações - docentes e discentes - as TIC podem ser percebidas como um excelente recurso pedagógico, uma vez que é na ação entre esses atores que a aprendizagem se efetivará. Entretanto, "a escolha de determinado tipo de tecnologia altera profundamente a natureza do processo educacional e a comunicação entre os participantes” (KENSKI, 2007, p. 45). Portanto, para que a aprendizagem se realize, é necessária a compreensão do que significa 'usar adequadamente' as TIC como recurso mediador das situações pedagógicas, pois

\begin{abstract}
a evolução tecnológica não se restringe apenas aos novos usos de determinados equipamentos e produtos. Ela altera comportamentos. A ampliação e a banalização do uso de determinada tecnologia impõem-se à cultural existente e transformam não apenas o comportamento individual, mas o de todo o grupo social. A descoberta da roda, por exemplo, transformou radicalmente as formas de deslocamento, redefiniu a produção, a comercialização e a estocagem de produtos e deu origem a inúmeras outras descobertas (KENSKI, 2007, p. 21).
\end{abstract}

Vale a pena lembrar que não são somente as mudanças comportamentais a serem alteradas pela tecnologia. Quando pensamos em TIC, mais especificamente, somos também surpreendidos pela velocidade com que a sua atualização e evolução ocorrem. Por isso, para Kenski (2007), o esforço educacional não se restringe somente a rever as práticas pedagógicas que deem conta de incorporar as TIC, mas também que deem conta das mudanças que não param de ocorrer. Como aponta a autora,

[...] as tecnologias estão em permanente mudança, a aprendizagem por toda a vida torna-se consequência natural do momento social e tecnológico em que vivemos. [...] Abrir-se para novas educações resultantes de mudanças estruturais nas formas de ensinar e aprender possibilitadas pela atualidade tecnológica é o desafio a ser assumido por toda a sociedade (KENSKI, 2007, p. 41).

E nesse ponto, a citação de Kenski remete-nos ao que Pierre Lévy, já em 1999, preconizava a respeito das novas relações com o saberes e com a educação que surgiu a partir do advento das TIC. "Pela primeira vez na história da humanidade, a maioria das competências adquiridas por uma pessoa no início de seu percurso profissional estarão 
obsoletas no fim de sua carreira" (LÉVY, 1999, p. 157). Em outras palavras, a ideia que Lévy traz à luz da discussão é que nossa relação com o saber e a forma como aprendemos deve-se adaptar ao fluxo das tecnologias que ora temos ao nosso dispor. Para este autor,

\begin{abstract}
o ciberespaço suporta tecnologias intelectuais que amplificam, exteriorizam e modificam numerosas funções cognitivas humanas [...] Essas tecnologias intelectuais favorecem: novas formas de acesso à informação, [...]novos estilos de raciocínio e de conhecimento[...] que não advém nem da dedução lógica nem da indução a partir da experiência (ibidem).
\end{abstract}

Por meio de softwares e documentos distribuídos em rede, o conhecimento é compartilhado entre um grupo maior de indivíduos o que acaba por potencializar a inteligência coletiva dos grupos humanos (LÉVY, 1999). É nesse ciberespaço permeado pelos mais diversos recursos fornecidos pelas TIC que cursos na modalidade a distância tiveram sua maior expansão nos últimos anos. No Brasil, a meta do Ministério da Educação e Cultura em 2014 era o de triplicar o número de alunos inscritos em cursos públicos de EAD, indo de 210 mil para 600 mil (TEATINI, 2012). Assim, trataremos em seguida do uso do AVA para o ensino virtual por ser parte integrante dessa modalidade, além de poder ser suporte para o ensino presencial.

\title{
2. Sobre Ambientes Virtuais de Aprendizagem (Ava)
}

O AVA é conhecido por ser parte integrante principalmente de cursos na modalidade de educação a distância (doravante, EAD). Nesta modalidade, por vezes, as interações mediadas por "meios de comunicação e as tecnologias interativas, dos correios à telepresença" (TORI, 2010, p. 26) quebram as relações de hierarquia entre alunos e professores e facilitam a aproximação entre os próprios os alunos.

A fim de apresentar um panorama sobre os recursos tecnológicos utilizados em curso na modalidade à distância, Dalmau (2007) elaborou um quadro explicativo (Quadro 1) das gerações da EAD, indicando que o salto entre uma geração e outra envolvia mudanças paradigmáticas relacionadas com as diversas mídias e tecnologias.

\section{Quadro 1 - Gerações da Educação a Distância}

\begin{tabular}{|l|l|}
$\begin{array}{l}\text { Primeira Geração Cursos } \\
\text { por correio }\end{array}$ & $\begin{array}{l}\text { EAD baseada essencialmente no uso de materiais impressos } \\
\text { com a comunicação acontecendo durante o processo de } \\
\text { ensino-aprendizagem, via correio. }\end{array}$
\end{tabular}




\begin{tabular}{|l|l|}
\hline $\begin{array}{l}\text { Segunda Geração Novas } \\
\text { Mídias/Universidades }\end{array}$ & $\begin{array}{l}\text { Inicia quando as grandes universidades foram criadas na } \\
\text { década de 1970, especialmente para oferecer cursos à } \\
\text { distância por rádio e televisão para um enorme público de } \\
\text { estudantes. }\end{array}$ \\
\hline $\begin{array}{l}\text { Terceira Geração EAD } \\
\text { online }\end{array}$ & $\begin{array}{l}\text { Inclui o uso de computadores e a possibilidade de } \\
\text { comunicação entre os participantes acontecer } \\
\text { simultaneamente (em tempo real, com transmissão de imagem } \\
\text { e som) por meio de videoconferência. }\end{array}$ \\
\hline Quarta Geração (2000) & $\begin{array}{l}\text { A grande capacidade de processamento dos computadores a a } \\
\text { velocidade das linhas de transmissão interferem na } \\
\text { apresentação do conteúdo e interações. }\end{array}$ \\
\hline Quinta Geração (2001) & $\begin{array}{l}\text { Uso de agentes inteligentes, equipamentos wireless e linhas } \\
\text { de transmissão eficientes. Organização e reutilização dos } \\
\text { conteúdos. }\end{array}$ \\
\hline
\end{tabular}

Fonte: Adaptado de Dalmau (2007, p. 26-27).

O AVA entraria nessas duas últimas gerações apontadas por Dalmau (2007). Nossa proposta de pesquisa, que culminou com a produção deste artigo, foi o de pensarmos a questão do ciberespaço, o uso das TIC, as possibilidades de interação dentro de tal espaço entre os indivíduos e a crença de que conhecimento não pode ser resumido a uma mera transferência de conteúdos.

Com base no ciberespaço, cursos de EAD têm, nas TIC, o suporte para interação e aproximação dos indivíduos, especialmente por meio dos AVA. Considerados como comunidades virtuais do ciberespaço com foco no aprendizado, um AVA é o local onde podem ocorrer situações de ensino e aprendizagem, ao mesmo tempo em que os indivíduos participantes dessas comunidades podem compartilhar interesses e objetivos em comum, ainda que estejam separados geograficamente e de forma assíncrona. Maia (2010) acredita que um AVA compartilhado por grupos virtuais pode ser uma experiência rica, dada a heterogeneidade de culturas que podem ali se encontrar.

O encontro desterritorializado é a marca de uma comunidade num AVA. Ainda que virtual, “um real fantasmagórico, latente” (LÉVY, 1996, p. 16), “ a virtualização submete a narrativa clássica a uma prova rude: unidade de tempo sem unidade de lugar, [...] continuidade de ação apesar de uma duração descontínua" (LÉVY, 1996, P. 21). Um AVA é um ponto de convergência de mídias diversas cujos elementos, num primeiro momento, parecem incompatíveis entre si. Para Almeida (2006, p. 204), 
A educação com o uso da TIC e a EAD por meio da TIC permitem aproximar elementos [...] como digital e analógico, interior e exterior, proximidade e distância, forma e conteúdo, etc. favorecendo estabelecer interrelações entre eles sem que cada elemento perca sua identidade.

Nesse sentido, Teperino et al. (2006) acreditam que qualquer que seja o formato de um curso de EAD, é indiscutível a importância da dialogicidade na comunicação no processo de aprendizagem, sejam quais forem as ferramentas utilizadas em um AVA, de modo síncrono (como salas de bate-papo ou aulas ao vivo com comunicação via telefone ou internet) ou assíncrono (como fóruns de discussão ou e-mails) para registro e acessos futuros. Em outras palavras, é por meio desses canais de comunicação que se estimula o constante feedback entre professores e alunos e a comunicação entre os próprios alunos. E Almeida (2006, p. 205) ainda observa que

O potencial interativo do uso da TIC no ato pedagógico se revela na possibilidade de criação dialógica e intersubjetiva propiciada pelas interações entre pensamentos, conceitos, imagens, mídias e idéias, nas quais o sujeito atua de forma consciente com os objetos de conhecimento.

A interação e interatividade, entretanto, não estão limitadas ao campo de aplicação das TIC, mas a todo evento de comunicação. Para Silva (2000), é por meio da interatividade que um indivíduo abandona a posição de um ser passivo para assumir a condição de um agente ativo. Complementando a ideia da autora, Almeida (2006, p. 205) afirma que "a interatividade se apresenta como um potencial de propiciar a interação, mas não como um ato em si mesmo". Os processos de interação são recorrentes em EAD, mesmo quando nos referimos aos meios de comunicação tais como rádio, televisão e no envio de material impresso, mídias essas ainda amplamente utilizadas. Ainda que sejam formas de interação unidirecional, tal formato "favorece a disseminação e a democratização do acesso à educação em diferentes níveis, permitindo atender crescente parcela da população que busca a formação inicial ou continuada, a fim de adquirir condições de competir no mercado de trabalho" (ALMEIDA, 2006, p. 206).

Mas é no espaço da cibercultura que as TIC ganham "potencialidade por conta da plasticidade do digital. As interfaces de conteúdo e de comunicação dos AVA permitem interatividade e autoria" (SANTOS, 2010, p. 41). Especialmente após o advento da Web 2.0, tornou-se possível ao seu usuário não somente obter informações, mas também produzir e publicar conteúdos. De acordo com McLeod e Vasinda (2008, p. 4), 


\begin{abstract}
a Web 2.0 pode ser comparada a um diálogo, uma discussão empolgante em sala de aula ou uma comunicação bidirecional. É também o local no qual as barreiras para produzir conteúdos baseados na Web são tão poucas que tudo o que uma pessoa precisa é o desejo de produzir alguma coisa. Ao usar blogs, wikis, podcasts e outras ferramentas da Web 2.0, os indivíduos agora falam de igual para igual com empresas e organizações e, o mais importante, têm o mesmo poder.
\end{abstract}

Santos (2010), por outro lado, chama a nossa atenção ao apontar para o fato que a potencialidade interativa das TIC online somente se realiza se os indivíduos que compartilham um AVA, permitem a comunicação e, efetivamente, usem os recursos ali disponíveis para que as questões relacionadas ao distanciamento geográfico, assim como as relacionadas à temporalidade sejam superadas.

Em se tratando da questão da interação entre os usuários de um AVA, não podemos deixar de mencionar os estudos sócio interacionistas propostos por Vygotsky. Entende-se por "interacionismo" como uma concepção do desenvolvimento humano que surge como uma alternativa às concepções de características paradoxais, o inatismo e o ambientalismo. Enquanto o inatismo e o ambientalismo são excludentes em relação à predominância de aspectos biológicos ou ambientais na formação dos indivíduos, o interacionismo irá prescrever que tanto estes quanto aqueles aspectos são de igual importância. Vygotsky (2004) observou que, enquanto os animais adaptam-se ao meio de forma passiva, o homem participa ativamente na adaptação de si ao meio que o rodeia e tem na origem dos instrumentos que cria a utilização de signos. Segundo o autor, "a invenção e uso de signos como meios auxiliares para solucionar um dado problema psicológico (lembrar, comparar coisas, relatar, escolher, etc) é análoga à invenção e uso de instrumentos, só que agora no campo psicológico" (VYGOSTSKY, 1998, p. 70).

O signo constitui-se, portanto, no elemento mediador entre o homem e os objetos. Podemos perceber a mediação na maioria das ações praticadas pelo homem e pode servir para determinar a extensão do papel dos instrumentos, dos signos e dos outros, na relação dos indivíduos. A mediação é, portanto, o motor do desenvolvimento ontogenético do potencial humano e se pensarmos no caráter semiótico da mediação, iremos observar que a transmissão de conhecimentos acumulados ao longo da história da humanidade não somente entre os indivíduos, mas também entre os psiquismos destes é a condição primeira e sem a qual não se estabelecem os processos da educação. Sendo assim, se pensarmos a linguagem, enquanto

\footnotetext{
5 Tradução livre: "Web 2.0 can be compared to a dialogue, an engaging class discussion or two-way communication. It is also one in which the barriers to producing Web-based content are so low that all one needs is the desire to produce it. By using blogs, wikis, podcasts, and other Web 2.0 tools, individuals now have an equal voice with businesses and organizations, and importantly have equal power."
} 
sistema simbólico de alta complexidade mais utilizado pelos indivíduos, é ela que desempenhará um papel preponderante na ação recíproca entre inteligência e o comportamento humano. Ao pontuarmos a importância dada por Vygotsky às questões de linguagem, pretendemos dar subsídios ao uso da língua nas interações mediadas pelas TIC. Mas antes apresentaremos algumas questões a respeito da concepção de língua na qual acreditamos e que norteia nossas práticas enquanto docentes de língua inglesa.

\section{Concepção de Língua e Tecnologia}

Como o foco da pesquisa foi o ensino/aprendizagem de línguas estrangeiras, acreditamos ser essencial uma reflexão sobre concepções de língua que permeia as salas de aula, as práticas dos professores e os livros didáticos.

Apesar de voltarmos nossa atenção ao ensino de língua inglesa, que foi o objetivo deste estudo, acreditamos que a discussão nesta parte do trabalho seja pertinente a qualquer ensino de línguas. Já que o(a) aluno(a) geralmente aprende uma língua para comunicar-se, acreditamos que não basta apenas o(a) professor(a) de línguas prender-se à estrutura da língua.

$\mathrm{Na}$ instituição em que a pesquisa ocorreu, o livro didático adotado nas aulas de língua inglesa utiliza-se da abordagem comunicativa, que coloca a língua em uso em contextos específicos e "a língua é entendida como meio de comunicação" (JORDÃO, 2013, p. 72). Assim, esta abordagem apresenta diversos exemplos de estruturas linguísticas em contextos limitados, não dando a oportunidade ao aluno para refletir sobre situações diferentes daquelas apresentadas no livro. A(o) aluno(a), basta memorizar e fazer adaptações necessárias dentro destes contextos. Segundo Duboc (2012), “o que a abordagem comunicativa acaba por priorizar constitui o uso correto e apropriado de estruturas linguísticas para cada situação, levando-nos a interpretá-la como uma abordagem prescritiva e refém de situações ideais." (2012, p. 37). Assim, esta abordagem restringe o(a) aluno(a) a certas construções e não o(a) incentiva a acreditar que outras possibilidades possam ser possíveis. Além disso, por mais que as situações presentes no livro didático possam ser desconfortáveis, os personagens sempre serão educados, deixando possíveis conflitos de lado. Cabe a(o) professor(a) problematizar tais questões dentro do livro didático e ajudá-los a construir um conhecimento que não siga apenas as estruturas apresentadas nesses materiais. Além disso, o livro em questão coloca o falante nativo como modelo único a ser seguido. 
Segundo Leung (2005), estima-se que existem cerca de 300-500 milhões de falantes de inglês nativos, contra cerca de quase um bilhão de pessoas que falam inglês como língua estrangeira para as mais variadas necessidades (LEUNG, 2005, p. 133). Assim, focar apenas no falante nativo, quando a probabilidade de nosso(a)s aluno(a)s falarem com algum sujeito que não tenha a língua-alvo como língua materna, é impedir que uma riqueza de olhares esteja fora da sala de aula. Mais uma vez, seria papel do(a) professor(a) trazer estes outros usos de língua para dentro do seu contexto educacional.

Assim, acreditamos que a melhor maneira de ensino seria expor os alunos ao aprendizado por meio de uma concepção de língua como discurso (BAKHTIN, 2003; VOLOCHÍNOV, 2009; MAKONI; PENNYCOOK, 2007). Ou seja, perceber uma língua que usamos para comunicação, interação, para construção de nossa identidade e não uma língua que é composta apenas de estruturas sintáticas, memorização de léxico e regras gramaticais. Segundo Volochínov (2009, p. 98), "na realidade, não são palavras o que pronunciamos ou escutamos, mas verdades ou mentiras, coisas boas ou más, importantes ou triviais, agradáveis ou desagradáveis". O autor prevê que utilizamos a língua como discurso a todo momento. Assim, para o ensino de língua estrangeira, acreditamos ser mais pertinente para quem está aprendendo esta língua o contato sob essa perspectiva. Concordamos com Volochínov (2009) ao afirmar que todo signo (palavra) é social, ou seja, é pela interação, do contato com o outro que a comunicação acontece. Por isso não podemos dissociar o signo "das formas concretas da comunicação" (Ibid., p. 42).

Faraco, já em 1997, afirmava que se pensarmos a “(...) autonomia do aprendiz como parte do processo de sua imersão no espaço da cidadania”. Também, precisamos pensar que "no contexto específico da educação linguística, passa pela elaboração de práticas que rompam com a visão estática do normativismo" (FARACO, 1997, p. 58). Segundo o autor, para o(a) aluno(a) ser autônomo e conseguir seu papel como cidadão nas ou por meio das aulas de língua estrangeira, é necessário que não seja seguido somente o modelo do normativismo, pois Faraco (1997) considera-o uma forma de perceber a língua como antidemocrática, caminho esse contrário ao que estamos tentando trilhar aqui. Para tanto, precisamos fugir de um caminho que considere a língua como pétrea, fixa que não muda com o tempo, de acordo com Bruz (2012).

Se pensarmos numa concepção de língua como discurso, precisamos preparar nosso(a)s aluno(a)s para o inesperado, pois nem sempre os indivíduos envolvidos na comunicação agem da mesma maneira todo o tempo ou de uma forma que já nos é 
conhecida. Como coloca Pennycook (2012), a língua pode aparecer de forma inesperada, em lugares inesperados, em interações inesperadas. Concordamos com Pennycook (2007), ao afirmar que "todas as línguas são construções sociais" (PENNYCOOK, 2007, p.1), assim como complementa Blommaert (2005) que "discurso é língua em ação" (p. 2); “compreende todas as formas de atividade semiótica humana significativa", conectadas com aspectos sociais, culturais e históricos (BLOMMAERT, 2005, p. 3).

Dentro desta perspectiva, acreditamos que o AVA pode ser uma ferramenta para o(a) aluno(a) estar em contato com esta língua em uso, meio no qual muitas possibilidades podem ocorrer e não apenas aquelas previstas pelo livro ou pelos professores. Para tanto, depende do(a) professor(a) guiar este uso para que o(a)s aluno(a)s possam explorar ambientes virtuais e encontrarem a língua em uso em ambientes autênticos e que sejam de seus interesses. Por isso, neste estudo qualitativo, de natureza interpretativista, analisamos como o AVA, na voz dos alunos, foi utilizado em aulas de inglês como língua estrangeira, em um curso superior e se esta ferramenta conseguiu atingir o objetivo de expor o(a)s aluno(a)s a diferentes usos da língua.

\section{A Pesquisa}

O objetivo da pesquisa que deu origem às discussões apresentadas neste artigo era o de averiguar como um AVA poderia trazer a possibilidade de um estudo de língua em que os alunos estejam em contato com a língua inglesa em outros ambientes fora da sala de aula. Além disso, pretendia-se que o uso deste ambiente virtual incentivasse o contato com a língua estudada em uso e possibilitasse o trabalho dos professores com uma concepção de língua como discurso. Após o uso do AVA durante dois semestres por professoras de inglês do curso de Secretariado Executivo Trilíngue, em uma instituição privada de Ensino Superior em Curitiba, foi elaborado um questionário sobre o uso desta ferramenta. Esses questionários foram respondidos pelos 24 aluno(a)s das turmas de Inglês 1 e de Inglês 3.

Neste artigo, por questões de espaço, analisaremos apenas uma parte deste questionário e que contempla uma das perguntas feitas em relação à motivação dos alunos em usar esta ferramenta em casa, e sobre os aspectos positivos e negativos da realização de atividades em um ambiente virtual. Além disso, observamos como as atividades dentro do AVA foram disponibilizadas. 


\subsection{O AVA e o Ensino de Inglês}

As professoras envolvidas no ensino de inglês das turmas pesquisadas utilizaram o AVA durante dois semestres e criaram atividades para serem disponibilizadas em rotas de aprendizagem. Uma rota de aprendizagem é um roteiro de estudos que apresenta algumas tarefas a serem realizadas pelos alunos. Alencar (1990, apud SCHNEIDER, MEDEIROS e URBANETZ, 2009) acredita que a partir de uma rota de aprendizagem, o(a) aluno(a) pode "levantar questões, elaborar e testar hipóteses, discordar, propor interpretações alternativas, avaliar criticamente fatos, conceitos, princípios, ideias". O sucesso no uso das ferramentas disponíveis no AVA, assim como as atividades por elas mediadas depende de uma leitura atenta da rota de aprendizagem.

Conforme discutido anteriormente, acreditamos que o AVA possa ser uma ferramenta que ajude o(a) professor(a) a colocar seus aluno(a)s em contato com a língua em uso, em ambientes autênticos e que gerem o interesse dos alunos por assuntos que sejam relevantes para cada sujeito. Assim, além do auxílio para o(a) professor(a), o(a) aluno(a) também poderia pesquisar outros assuntos e escolher onde encontrar informações relevantes . Desta forma, o AVA incentivaria a autonomia do(a) aluno(a) e também tornaria o estudo da língua mais atrativa e a agradável, pois o(a) aluno seria diretamente responsável pelos seus estudos.

Durante dois semestres, as professores utilizaram o AVA como suporte para suas aulas, postando atividades extras que abrangiam os temas da aula e as diferentes habilidades no aprendizado de uma língua (fala, escuta, escrita e leitura). Existia espaço para os alunos escreverem sobre alguns temas e postarem suas opiniões em fóruns escritos. Além do fórum escrito, havia também um de voz, espaço esse que permitia aos alunos gravarem em áudio sobre opiniões e comentários e que tratavam de assuntos discutidos em sala de aula.

Ao final destes semestres, as professoras solicitaram aos alunos que respondessem a um questionário, a fim de verificar se o uso do AVA foi bem recebido pelos alunos e quais aspectos poderiam ser modificados. Uma das perguntas abertas questionava sobre aspectos positivos e negativos do uso do AVA. Ao analisarmos as respostas do(a)s aluno(a)s, a maioria apontou mais aspectos positivos do que negativos. Estes últimos foram relacionados às questões de ordem técnica (acesso à internet, computadores com capacidade de abrir os sites recomendados, etc.). Isso fornece indícios que podem confirmar a nossa percepção inicial a respeito da tecnologia como parte integrante das nossas vidas, pois o uso do AVA em si não sofreu rejeição por partes dos alunos. 
Porém, ainda que os aspectos positivos tivessem suplantado os negativos, o que chamou a nossa atenção foi o fato de os alunos mencionarem, em sua maioria, exercícios gramaticais e/ou estruturais em suas respostas. Com exceção de dois alunos que responderam: "com essas ferramentas temos mais contato com a língua inglesa" ou "contato com a língua fora de sala de aula", as demais respostas deram ênfase às questões estruturais da língua ou a preocupações com provas e avaliações.

Algumas respostas basearam-se basicamente em termos linguísticos: "ampliação do conhecimento escrito, auditivo e oral" e "aumento de vocabulário, melhoria na pronúncia". São considerados positivos os aspectos que reforçam o trabalho com exercícios estruturais e que levam os alunos a construírem suas respostas nesse sentido. Isso reflete uma concepção estruturalista de língua e que está presente na abordagem do livro didático utilizado em sala de aula. Apesar dos mesmos temas estarem presentes tanto no livro quanto nas aulas presenciais e nas atividades disponibilizadas nas rotas de aprendizagem do AVA, o aprofundamento de temas discutidos em sala não apareceu como resposta dos alunos. Apenas o trabalho de estruturas e de vocabulário é mencionado .

Estas respostas nos levam a acreditar que o AVA tenha sido usado apenas como reforço aos conteúdos gramaticais, com foco na pronúncia e memorização de léxico referente às lições do livro. Em nenhum momento, os alunos responderam algo que nos levasse a acreditar que a língua como discurso tivesse sido trabalhada neste ambiente virtual. Tampouco, os alunos responderam sobre aprender a procurar informações diferentes ou sobre aprender sobre culturas diferentes. O uso de um ambiente online para estimular os estudos não foi explorado. Os alunos precisavam apenas abrir a página da internet fora da sala de aula, seguir as instruções e fazer exercícios. Alguns alunos, inclusive, mencionaram o fato de usarem livro de exercícios concomitantemente ao uso do AVA; ou seja, o AVA não passava de uma lista e exercícios.

A voz dos alunos não aparecia nas rotas de aprendizagem, com exceção dos fóruns em que era solicitado ao aluno pesquisar e, num momento posterior, relatar sobre diferentes temas abordados. Porém, em nenhum momento, isto foi relevante para os que responderam ao questionário. Além disso, esperava-se que os alunos interagissem entre si nestes espaços. Mas isso não ocorreu de forma espontânea, muito provavelmente pela falta de estímulo por parte dos professores que levassem os alunos a adotarem tal comportamento. O que reforça que apesar das professoras guiarem as atividades para trabalharem língua como discurso 
(BAKHTIN, 2003; VOLOCHÍNOV, 2009; MAKONI; PENNYCOOK, 2007), os(as) alunos(as) não refletiram isso em suas respostas.

\section{Conclusões e Possibilidades}

Sabemos que um ambiente virtual é limitado; porém, existem maneiras de apresentar assuntos sobre temas tratados em sala de aula. Dessa forma, quem está aprendendo a língua poderá trilhar seus próprios caminhos e ter acesso a outras opiniões, ideias, e que impactem as suas próprias construções. Observamos nas respostas dadas pelos alunos que o AVA serviu apenas como uma forma de extensão do uso do livro em sala de aula, uma vez que ficou nítida a preocupação com o conteúdo gramatical trabalhado em sala, e também serviu como um recurso extra para estudar para provas.

Com isso, concluímos que uma possibilidade seria propiciar aos alunos um espaço real de manifestação de modo que suas vozes pudessem realmente serem ouvidas ao longo do uso do ambiente virtual e que houvesse maior liberdade para a busca de informações, além do que foi disponibilizado nas rotas de aprendizagem. O AVA acaba funcionando como uma extensão da sala de aula normativista na qual a concepção de língua é estruturalista. Para o aluno colocar sua voz dentro desses ambientes, seria necessário que isso fosse já uma prática instaurada em sala de aula. Podemos perceber que o trabalho realizado em ambiente virtual reflete a concepção de língua utilizada em sala de aula, já que se aproxima dos exercícios constantes do livro didático. Para modificar o uso do AVA de modo a torná-lo um ambiente realmente significativo para o aprendizado é preciso, antes de tudo, modificar a concepção de língua de todo o processo de ensino, a partir do próprio espaço da sala de aula presencial.

\section{Referências}

ALMEIDA, M. E. B. Educação, ambientes virtuais e interatividade. In: SILVA, Marco (org). Educação online: teorias, práticas, legislação, formação corporativa. São Paulo: Edições Loyola, 2006, p. 203-217.

ALENCAR, E. M. L. S. de. Como desenvolver o potencial criador: um guia para a liberação da criatividade em sala de aula. Petrópolis, RJ: Vozes, 1990.

BAKHTIN, M. (VOLOCHÍNOV, V. N.). Marxismo e filosofia da linguagem. São Paulo: Editora Hucitec, 2009.

BAKHTIN, M. (VOLOCHÍNOV). Estética da criação verbal. São Paulo: Martins Fontes, 2003. 
BASTOS, J. A. A. (Org). Educação Tecnológica: Imaterial \& Comunicativa. Curitiba: Cefet-PR, 2000. Coletânea Educação \& Tecnologia.

BLOMMAERT, J. Discouse: A critical Introduction. Cambridge: Cambridge Universityt Press, 2005.

BRITO, G. S.; PURIFICAÇÃO, I. Educação e Novas Tecnologias: um Repensar. Curitiba: IBPEX, 2006.

BRUZ, I. M. Análise de livros didáticos de língua inglesa sob o viés da interculturalidade. 2012. 105 f. Dissertação (Mestrado em Educação), UFPR, Curitiba, 2012.

COSTA, S. R. D. O papel da interação social na aprendizagem do aluno com Transtorno de Déficit de Atenção/Hiperatividade TDAH: o caso do CENEP - HC/UFPR. Mestrado em Educação. Setor de Educação. Universidade Federal do Paraná, UFPR, Curitiba: 2006.

COUTINHO, M. T. C. Educação a distância e mediação semiótica: algumas relações necessárias. In: I Colóquio de Semiótica da Faculdade de Letras da UFMG, 2002, Belo Horizonte. Anais. Belo Horizonte : FALE/UFMG, 2001. p. 1-21. Disponível em: <http://www.letras.ufmg.br/site/publicacoes/LIVROCOLOQSEM5.doc>. Acesso em: 27 out. 2009.

DALMAU, M. B. L. Introdução à educação a distância. Florianópolis: Departamento de Ciências da Administração/UFSC, 2007

DUBOC, A. P. M. Atitude Curricular: Letramentos Críticos nas Brechas da Formação de professores de Inglês. 2012. Tese (Doutorado em Letras): Universidade de São Paulo, São Paulo, 2012.

FARACO, C. A. Linguagem, escola e modernidade. In: GHIRALDELLI. Jr, P. (Org.) Infância, escola e modernidade. São Paulo: Cortez; Curitiba: Editora UFPR, 1997.

.Linguagem \& diálogo: as ideias linguiísticas do Círculo de Bakhtin. São Paulo: Parábola Editorial, 2009.

JORDÃO, C. M. Abordagem comunicativa, pedagogia crítica e letramento crítico - farinhas do mesmo saco? In: HILSDORF ROCHA, Cláudia; FRANCO MACIEL, Ruberval.(Orgs.) Língua estrangeira e formação cidadã: por entre discursos e práticas. Campinas SP: Pontes Editora, 2013.

KENSKI, V. M. Educação e tecnologia: o novo ritmo da informação. Campinas, SP: Papirus, 2007. Coleção Papirus Educação.

LÉVY, P. O que é virtual? . Trad. Paulo Neves. São Paulo: Ed. 34, 1996. (Coleção Trans).

Cibercultura. Trad. Carlos Irineu Costa. São Paulo: Ed. 34, 1999. (Coleção Trans).

LEUNG, C. Convivial Communication: recontextualizing communicative competence. International Journal of Applied Linguistics: Oxford, v.15, n. 2, p. 119-144, 2005. 
MAGNO E SILVA, W. M. Livros didáticos: fomentadores ou inibidores da autonomização? In: DIAS, R.; CRISTOVÃO, V. L. L. (ORG.) O livro didático de língua estrangeira: múltiplas perspectivas. Campinas, SP: Mercado das Letras, 2009.

MAIA, M. C. O uso da tecnologia de informação para a educação a distância no ensino superior. Tese (Doutorado em Administração de Empresas). Escola de Administração de Empresas de São Paulo da Fundação Getúlio Vargas. São Paulo, 2003.

MAKONI, S.; PENNYCOOK, A. Disinventing and Reconstituting Languages. Clevedon: Multilingual Matters, 2007.

MCLEOD, J.; VASINDA, S. Critical literacy and web 2.0: exercising and negotiation power. Computers in the Schools: Interdisciplinary Journal of Practice, Theory, and Applied Research V. 25, n.3-4, 2008. Disponível em: < http://www.tandfonline.com/doi/pdf/10.1080/.U36ZwlVdWSo> Acesso em 22 maio 2014.

MONTE MÓR, W. Multimodalidades e comunicação: antigas novas questões no ensino de línguas estrangeiras. Letras \& Letras: Uberlândia, UFU, v. 26, p. 469-478, 2010.

MORAES, M. C. Novas tendências para o uso das tecnologias da informação e da comunicação na educação. In: FAZENDA, I. et al. Interdisciplinaridade e novas tecnologias. Campo Grande: UFMS, 1998.

PENNYCOOK, A. Language and mobility: Unexpected Places. Bristol, Multilingual Matters, 2012.

PIMENTEL, N. M. Introdução à educação a distância. Florianópolis: SEAD/UFSC, 2006.

PORCELLATO, A. M. Aspectos culturais e interculturais nos Livros Didáticos de Língua Estrangeira: Italiano e Inglês em Confronto. 2013. 168 f. Dissertação (Mestrado em Linguística), UFMG, Belo Horizonte, 2013.

RIBEIRO, A. E. Ler na tela - Letramento e novos suportes de leitura e escrita. In: COSCARELLI, Carla Viana; RIBEIRO, Ana Elisa (Orgs.). Letramento digital: aspectos sociais e possibilidades pedagógicas. Belo Horizonte: Ceale; Autêntica, 2005. p. 125-150.

SANTOS, E. Educação online para além da EAD: um fenômeno da cibercultura. In: SILVA, Marco; PESCE, Lucila; ZUIN, Antônio (Orgs.). Educação online: cenário, formação e questões didático-metodológicas. Rio de Janeiro: Wak editoria, 2010. p. 29-48.

SCHNEIDER, E.; MEDEIROS, L; URBANETZ,S. O Aprender e o Ensinar em EaD por meio de Rotas de Aprendizagem. In: $15^{\circ}$ Congresso Internacional $A B E D$ de Educação a Distância, 2009, Fortaleza. Anais. Fortaleza : ABED, 2009.

SILVA, Marco. Interatividade: uma mudança fundamental do esquema clássico da comunicação. In: Boletim Técnico do SENAC v. 26, n.3 (set/dez. 2002). Disponível em: <http://www.senac.br/informativo/bts/263/boltec263c.htm> Acesso 20 maio 2014. 
ROJO, R. (org.) Escola Conectada: Os Multiletramentos E As Tics. São Paulo: Parábola, 2013.

TEATINI, J.C. MEC promete triplicar matrículas em EAD e alcançar 600 mil alunos até 2014 [24 de abril, 2012]. São Paulo: Uol Educação. Entrevista concedida à Simone Harnik. Disponível em: < http://educacao.uol.com.br/noticias/2012/04/24/mec-promete-triplicarmatriculas-em-ead-ate-2014-e-alcancar-600-mil-alunos.htm> Acesso em 22 maio 2014.

TEPERINO, A. S. et al. Educação a distância em organizações públicas: mesa-redonda de pesquisa-ação. Brasília: ENAP, 2006.

TORI, R. Educação sem distância: as tecnologias interativas na redução de distâncias em ensino e aprendizagem. São Paulo: Editora Senac São Paulo, 2010.

VALENTE, J. A. Por que o computador na educação. In: VALENTE, J. A. (ORG.) Computadores e conhecimento: repensando a educação . Campinas: Gráfica da Unicamp, 1993.p. 24-44.

VEER, R.r; VALSINER, J. Vygotsky: uma síntese. 3. ed. São Paulo: Loyola, 1999.

VYGOTSKY, L. S. Pensamento e Linguagem. 2. ed. São Paulo: Martins Fontes, 1998.

VYGOTSKY, L. S.. A formação social da mente: o desenvolvimento dos processos psicológicos superiores. 6. ed. São Paulo: Martins Fontes, 1998a.

Teoria e método em psicologia. 3. ed. São Paulo: Martins Fontes, 2004.

WANG, X. et al. Globalization in the margins: towards a re-evaluation of language and mobility. Applied Linguistics Review. London, v. 5, n. 1, p. 23-44, 2014. 